\title{
A PRODUÇÃO DE UM DISCURSO DE NATUREZA NO PAMPA SOB O OHAR DA EDUCAÇÃO AMBIENTAL
}

\author{
SCHLEE, Renata Lobato ${ }^{1}$ \\ HENNING, Paula Correa ${ }^{2}$
}

\section{INTRODUÇÃO}

Este estudo, analisa o Pampa do RS, Uruguai e Argentina através de seu expoente cultural chamado gaúcho (gaucho). Entendendo que este sujeito expressa um discurso de natureza que é fabricado e produzido a partir dele e sua cultura. $\mathrm{O}$ Pampa, além de um território geográfico pode ser entendido como uma forma de ser e, de viver. Historicamente é um campo de saberes, lutas, disputas, chegadas e partidas. Constitui e é constituído por diversos atravessamentos.

São terras no extremo sul do continente da América do Sul, cercando áreas que compõe o Uruguai, Argentina, Chile e o sul do estado do Rio Grande do Sul no Brasil, e tem sua geografia predominantemente distinguida por relevos de planícies e coxilhas, matas de galeria e banhados. Algumas espécies endêmicas são encontradas nesses campos que compõe aproximadamente $700 \mathrm{mil} \mathrm{Km}^{2}$ (aqui incluindo o sul do Rio Grande do Sul, o Uruguai e parte da Argentina ${ }^{3}$ ). O Pampa como como tentamos apresentar nesta pesquisa, é entendido para além do conceito geográfico. É Guattari (1995) quem nos ajuda a refletir sobre esse conceito quando nos convida a reexamina-lo a partir de conjuntos que atravessam a relação entre o indivíduo e a subjetividade, trazendo-o como modos de viver padronizados. Ou seja, queremos explorar o território pampeano como uma composição histórica, como conjunto de diferentes fatores, que incluem maneiras de ser, de pensar, maneiras de viver já uniformizadas. O que pretendemos então, é de maneira rápida neste texto, levantarmos algumas considerações sobre a constituição do sujeito gaúcho e sua

Mestre e Doutoranda em Educação Ambiental - FURG. Integrante do Grupo de Estudo sobre Educação, Cultura, Ambiente e Filosofia - GEECAF / FURG. Bolsista CAPES. $\frac{\text { renataschlee@gmail.com }}{2}$

Professora Dra em Educação e Pesquisadora do Instituto de Educação, do Programa de Pós-Graduação Educação Ambiental e do Programa de Pós-Graduação Educação em Ciências da Universidade Federal do Rio Grande - FURG. Coordenadora do Grupo de Estudo sobre Educação, Cultura, Ambiente e Filosofia - GEECAF / FURG. paula.c.henning@gmail.com

ONG Amigos da terra. Site da internet: http:amigosdaterrabrasil.htm (consultado em junho 2009). 
fabricação de um discurso de Natureza. Para isto nos apoiaremos em alguns ensinamentos de Michel Foucault que nos ensina algumas ferramentas para análise do discurso e também problematizações para o entendimento da própria história.

\section{UM DISCURSO DE NATUREZA NO PAMPA}

O desfio de entender a história não é simples. Podemos começar nos perguntando sobre o que é a própria história. Colocar a posição que assumimos no entendimento sobre a história passa a ser estratégico para que os passos percorridos nesta pesquisa fiquem mais claros. Tal fato nos leva também a querer salientar, de início, o quanto é desafiador escrever sobre a história.

Quando falamos de história, pensamos em acontecimentos passados que podem ser relatados em nosso presente. Pensamos ter a capacidade de retratar esse passado exatamente como ocorreu em tempos idos. Os fatos históricos vão sendo contados e construídos como verdades absolutas e assim vamos construindo entendimentos sobre o que passou, tomando esses acontecimentos como revelados, desvendados e desvelados.

Sobre um outro olhar para os acontecimentos históricos, pensamos em nossos próprios limites quando estudamos e analisamos um determinado tempo histórico. Entendemos que fazemos e construímos narrativas sobre esses tempos através de documentos e testemunhos. Sendo assim, há sempre uma incompletude a ser considerada. Como nos lembra Veyne (2008), há sempre uma defasagem entre a reflexão da narrativa histórica e as vivências, próprias do tempo em que ocorreram. A análise histórica, na capacidade e potencialidade expressada, evidencia posições e escolhas que vamos assumindo na construção dessa narrativa. São seleções documentais e de testemunhos que vamos executando e produzindo. São narrativas que expressam olhares, expressam tramas e atravessamentos selecionados de um espaço tempo. É como se pinçássemos os elementos que formam nossa narrativa. E, ao pinçar, selecionamos entre outros elementos aqueles com os quais queremos trabalhar nessa análise. Por isso, é possível dizer a história é feita também de escolhas e renúncias.

Atuamos, na análise histórica, assumindo posições. Assumimos posições de sujeito que anunciam de que lugar estamos falando e, portanto, nossa posição nas tramas e jogos de poder para e na execução da análise histórica. Concomitante, 
a narrativa vai também evidenciar os jogos de poder pinçados sobre aquele espaço tempo. São relações de poder que estão em evidência. $E$ isto, desloca 0 entendimento da história como desveladora das verdades do passado. Entendemos que não desvelamos verdades, mas assumimos uma seleção e compomos uma narrativa histórica. Construímos essa narrativa em meio a seleção que vamos executando. Construímos verdades? Sim, construímos verdades em nosso tempo. Construímos, nesta perspectiva verdades entendidas como provisórias. Portanto, as verdades históricas são temporárias e sujeitas a revisões, novos olhares e perspectivas. Sujeitas a novos pinçares, seleções, entendimentos e análises.

Assim, a história é assumida por nós, como campo de possibilidades. É no pinçar das fontes, no seu manuseio, nas tramas e entrelaçamentos que vamos construindo, de acordo com nossos critérios, o que chamamos de história.

Então, falar da história do Pampa do RS, Uruguai e Argentina é percebido neste trabalho como possibilidade de destacar algumas tramas e entrelaçamentos. É um pinçar construído na e pela pesquisa. No manuseio das fontes procurar a história do presente e as especificidades que se apresentam em jogos e lutas, estratégias e táticas de poder.

Encaramos a história do Pampa como plural e sujeita a diferentes perspectivas. Vamos recortando as ações humanas em perspectivas temporais e espaciais, montamos narrativas que pretendemos coerentes. E, como nossa seleção depende dos nossos critérios, encaramos que a história é subjetiva. Encaramos que a história se dá como campo de possibilidades de interpretações.

Quando escolhemos pesquisar sobre o Pampa e sua cultura, sua natureza e o sujeito que se constitui e ao mesmo tempo é constituído nesses discursos, percebemos que estamos tentando selecionar e construir possibilidades de olhares. Atentamo-nos em cruzamentos de itinerários que se apresentam como possíveis no processo de pesquisa. Tencionamos as forças que se apresentam, tendo o problema de pesquisa "como o sujeito do Pampa fabrica um discurso de natureza a partir do dito e não dito?" Como o discurso de natureza no Pampa do RS, do Uruguai e Argentina vem se constituir como legítimo? Nosso olhar sobre o Pampa vem na tentativa de problematizar como se constitui o discurso de natureza do Pampa na atualidade, pois notamos na configuração desse território traços que são marcados através do dito e não dito e que se estabelecem em um discurso de natureza. 
Tomamos o discurso de Natureza do Pampa a partir dos ensinamentos de Foucault sobre análise do discurso, e temos como corpus empírico entrevistas com sujeitos pampeanos vinculados ao RS, Uruguai e Argentina e ainda, registros fotográficos efetuados pelos entrevistados ao representarem suas imagens do que é a natureza. Essas narrativas serão tomadas como enunciações sobre o Pampa e sua natureza.

Em conjunto as entrevistas, as imagens compõem a pesquisa no entendimento de que elas também nos dizem da representação desse território. Ditos e não ditos como forças que nos falam e nos constroem pelas representações de natureza que constituem e fabricam. Entendendo que essas próprias forças são ao mesmo tempo constituídas e fabricadas.

As fotografias e as entrevistas serão estudadas na possibilidade de reflexões e análises sobre o problema que levantamos através desse corpus empírico. É na análise das forças acionadas a partir desse corpus que vemos potência para o entendimento de como o sujeito pampeano percebe, constrói e fabrica um discurso de natureza. Diante da temática do problema e do corpus empírico apresentado notamos a possibilidade de enunciações que se ligam e se tornam fortes para a análise da formação discursiva em estudo: a natureza.

Para olhar para o Pampa de hoje, é preciso olhar para a história. Aqui o dito nos reporta olhar para a história com os olhos do presente através das entrevistas. Buscar e descrever o dito, esse recorte vai constituindo o discursivo desse corpus de pesquisa. Pretendemos colocar em evidência alguns enunciados, definir as regras que os constituem mais potentes entre outros, dentre as condições sociais, ambientais, econômicas etc. Nossa intenção é chegar ao discurso através desses enunciados, considerando-os como partículas desse discurso, enfim entender e descrever como o discurso de natureza se formou no Pampa.

O Pampa vem sendo bastante estudado nos últimos anos e caracterizado em suas diferentes expressões. A problemática socioambiental do Pampa vem sendo pauta de diferentes eventos e instituições através de estudos e trabalhos de cunho científico, artístico, literário, etc. Temos trabalhos elaborados sobre o Pampa que nos remetem a diferentes dissertações e teses, mas também temos inúmeros trabalhos e instalações artísticas sobre o mesmo. São atravessamentos que nos fazem pensar e questionar a construída dicotomia entre cultura e natureza. $O$ que no Pampa podemos dizer como natural? E, o que no Pampa podemos definir como 
cultural? Pois, entendemos que são definições e marcações que expressam um discurso de natureza que é fabricado e produzido na e pela cultura.

Tomamos a natureza como formação discursiva e é Foucault quem nos situa

\begin{abstract}
No caso em que se puder descrever, entre um certo número de enunciados, semelhante sistema de dispersão, e no caso em que entre os objetos, os tipos de enunciação, os conceitos, as escolhas temáticas, se puder definir uma regularidade (uma ordem, correlações, posições e funcionamentos, transformações), diremos, por convenção, que se trata de uma formação discursiva - evitando, assim, palavras demasiado carregadas de condições e consequências, inadequadas, aliás, para designar semelhante dispersão, tais como "ciência", ou "ideologia", ou "teoria", ou "domínio de objetividade". (FOUCAULT, 2002, p. 43)
\end{abstract}

Com esse problema de pesquisa colocado, chegamos a dois grandes questionamentos: 1. Como se estabelece a relação entre cultura e natureza na constituição do sujeito do Pampa? / 2. Como se entrelaçam os ditos e as fotografias pampeanas na fabricação de um discurso de natureza?

Buscamos o caráter construído, contingente, não transcendental do sujeito que vive no Pampa e fabrica esse discurso, entendendo que ao mesmo tempo, esse sujeito se constrói nesse processo. Esse discurso de natureza que sujeita o sujeito, mas que ao mesmo tempo é construído por ele será colocado em suspenso nesta pesquisa. Pois os discursos são invenções e como invenções se estabelecem em regimes de verdade. Regimes de verdade enquanto fabricação cultural. A verdade pode ser vista como um produto de relações de força, jogos de verdade em que algumas são dadas como corretas. E voltando ao que foi colocado no início deste texto, tentaremos entender algumas verdades produzidas historicamente sobre o Pampa e seu sujeito cultural, o gaúcho, ou gaucho, como é conhecido no Uruguai e Argentina. Como o sujeito pampeano produz esse discurso de natureza colocado na atualidade? Neste momento então, vamos nos debruçar sobre a história dessa formação cultural, procurar entender a produção desse sujeito cultural. Buscar as articulações entre a história e o discurso de natureza produzido e tomado como verdade.

É com Foucault (2002) que buscamos o entendimento de verdade, pois esse autor transporta para o sentido de invenção aquilo que se tinha por origem. Ou seja, passamos a encarar a verdade como possibilidade de invenção. Não buscaremos na história do Pampa do RS, Uruguai e Argentina a verdade absoluta, 
mas as verdades sobre natureza inventadas, fabricadas, narradas e assumidas como legítimas pelo sujeito pampeano nesse espaço específico: o Pampa. Assim, passamos a trabalhar com algumas condições de possibilidade para a formação do discurso de natureza. Trazendo a história, tentaremos estabelecer possíveis articulações ao discurso de natureza. Tentaremos escrever e descrever possíveis atravessamentos da história para o discurso de natureza.

O sujeito pampeano, o gaúcho, é um sujeito discursivamente construído, sendo um resultado, um produto cultural. Assim nos lançamos em sua história numa perspectiva que entrelace saberes e poderes e evidencie não só a sua própria fabricação enquanto sujeito, mas em como esse sujeito inventa um discurso de natureza.

Esse Pampa, para além de um território geográfico pode ser entendido como uma forma de ser, de viver. Constitui e é constituído por diversos atravessamentos culturais, geográficos, políticos, sociais, econômicos, biológicos... historicamente é um campo de saberes, lutas, disputas, chegadas e partidas. Dizemos que o gaúcho é uma figura cultural que se desenvolveu nos últimos séculos ao longo das pradarias do Pampa e aqui será buscado em sua singularidade e complexidade nos indagando sempre em que condições de possibilidade se constitui um discurso de Natureza nesse Pampa.

\section{EDUCAÇÃO AMBIENTAL COMO POSSSIBILIDADE DE OLHAR}

Como fomos tentando apresentar, para olhar para o Pampa de hoje, é preciso olhar para a história. Aqui o dito nos reporta olhar para o passado com os olhos do presente. Visibilizar e contar o dito, esse recorte vai constituindo o discursivo desse corpus de pesquisa.

Tomo o discurso de Natureza do Pampa a partir dos ensinamentos de Foucault sobre análise do discurso. Temos como corpus empírico entrevistas com sujeitos pampeanos vinculados ao RS, Uruguai e Argentina e ainda, registros fotográficos efetuados pelos entrevistados ao representarem suas imagens do que é a natureza. Essas narrativas são tomadas como enunciações sobre o Pampa e sua natureza. Assim, a partir de Foucault (2002) entendemos que se cria, a partir desse corpus discursivo uma possível formação discursiva sobre natureza. Com as fotografias pelo imagético e pelo contar das entrevistas, procuro cenas enunciativas 
que nos caminhos da Análise do Discurso de Foucault, dão visibilidade ao discurso (um discurso de natureza, revelando nossa forma de constituir a natureza). Ainda sobre o não discursivo, trago mais uma vez Foucault, quando nos ensina que por mais que se diga o que se vê, o que vemos não se instala no que se diz. É preciso buscar o infinito dessa tarefa... (FOUCAULT, 2007).

Dizemos que o gaúcho é uma figura cultural que se desenvolveu nos últimos séculos ao longo das pradarias do Pampa e aqui é buscado em sua singularidade e complexidade. Em que condições de possibilidade se constitui um discurso de Natureza nesse Pampa? A cultura, imiscuída aí, fabrica-se e auxilia, decisivamente, naquilo que chamamos de natureza.

Lembro que "entre os desafios que se apresentam à Educação Ambiental contemporânea está o de ultrapassar os aspectos puramente biológicos (evolutivos) da biodiversidade e incorporar os seus aspectos antropológicos, culturais, econômicos e políticos" (REIGOTA, 2010, p. 546), tomando a Educação Ambiental em sua articulação com os modos de vida, de ser e viver no ambiente do Pampa.

A educação ambiental pode ser o olhar reflexivo, analítico e provocativo dos processos culturais em seus atravessamentos socioambientais e ficará atenta ao como nos percebemos e constituímos através dos discursos. Discursos que nos desafiam a pensar em novas possibilidades de ser e estar, quiçá mais sustentáveis.

Tomamos a natureza como formação discursiva e é Foucault quem nos situa

No caso em que se puder descrever, entre um certo número de enunciados, semelhante sistema de dispersão, e no caso em que entre os objetos, os tipos de enunciação, os conceitos, as escolhas temáticas, se puder definir uma regularidade (uma ordem, correlações, posições e funcionamentos, transformações), diremos, por convenção, que se trata de uma formação discursiva - evitando, assim, palavras demasiado carregadas de condições e consequências, inadequadas, aliás, para designar semelhante dispersão, tais como "ciência", ou "ideologia", ou "teoria", ou "domínio de objetividade". (FOUCAULT, 2002, p. 43)

Buscamos o caráter contingente do sujeito do Pampa que fabrica esse discurso e se constrói nesse processo. Esse discurso de natureza que sujeita 0 sujeito, mas que ao mesmo tempo é construído por ele é colocado em suspenso nesta pesquisa. Pois os discursos são invenções e como invenções se estabelecem em regimes de verdade. Regimes de verdade enquanto fabricação cultural. A verdade pode ser vista como um produto de relações de força, jogos de verdade em 
que algumas são dadas como corretas. Como o sujeito pampeano produz esse discurso de natureza colocado na atualidade?

É com Foucault (2002) que buscamos o entendimento de verdade, pois esse autor transporta para o sentido de invenção aquilo que se tinha por origem. Ou seja, passamos a encarar a verdade como possibilidade de invenção. Não busco na história do Pampa do RS, Uruguai e Argentina a verdade absoluta, mas as verdades sobre natureza inventadas, fabricadas, narradas e assumidas como legítimas pelo sujeito pampeano nesse espaço específico: o Pampa. Assim, passamos a trabalhar com algumas condições de possibilidade para a formação do discurso de natureza e trazendo a história, tentamos estabelecer possíveis articulações ao discurso de natureza. Tentando escrever e descrever possíveis atravessamentos da história para o discurso de natureza.

\section{CONSIDERAÇÕES FINAIS}

Ao focar nos atravessamentos provocados pelo discurso de natureza, levantamos a complexidade das relações e interações socioambientais aí estabelecidas e construídas culturalmente. Pelo olhar da Educação Ambiental nos provocamos em reflexões que instrumentalizam um entendimento para a fabricação dos discursos. E, de um dos possíveis discursos de natureza no Pampa e sua problemática socioambiental.

Destacamos a importância de investigar as relações de força e as interações que vão se estabelecendo e constituindo verdades. Procuramos a constituição do discurso de natureza no Pampa e assim a possibilidade de evidenciar verdades que se fazem discursivamente.

\section{REFERÊNCIAS}

FOUCAULT, Michel. A verdade e as formas jurídicas. $3^{\mathfrak{a}}$ edição. NAU Editora. 2002.

. Arqueologia do saber. 6ª edição. Forense Universitária. 2002.

As palavras e as Coisas - Uma arqueologia das Ciências Humanas.

São Paulo. Martins Fontes, 2007. 
GUATTARI, Felix. As três ecologias. 5ª edição. Papirus. 1995.

REIGOTA, Marcos. A Educação Ambiental frente aos desafios apresentados pelos discursos contemporâneos sobre a natureza. Educação e Pesquisa, São Paulo, v. 36, no2, p. 539-553, maio/agosto, 2010.

VEYNE, Paul Marie. Como se escreve a história; Foucault revoluciona a história. 4ª edição. Editora Universidade de Brasília. 2008.

\section{CAPES}

Pesquisa realizada em processo de doutoramento com o apoio financeiro da Coordenação de Aperfeiçoamento de Pessoal de Nível Superior 